\title{
Diagnosing Pneumocystis carinii pneumonia by cytological examination of bronchoalveolar lavage fluid: report of 15 cases
}

\author{
JENNIFER A YOUNG, ${ }^{*}$ J W STONE, $†$ R J S MCGONIGLE, \\ J MICHAEL
}

From the Departments of *Pathology and $†$ Microbiology, the University of Birmingham, and the $\ddagger$ Department of Nephrology, Queen Elizabeth Hospital, Birmingham

SUMMARY Sixty episodes of pneumonia occurring in 53 immunosuppressed patients were investigated by bronchoalveolar lavage. Pneumocystis carinii was diagnosed on $15(25 \%)$ occasions. In all cases the Papanicolaou stained lavage fluid presented a distinctive appearance and contained abundant, often biphasic, staining, "honeycomb" debris, and few alveolar macrophages. The Grocott methenamine silver technique confirmed the presence of characteristic cystic organisms in the debris in all 15 instances. Cysts containing internal sporozoites were identified in Gram stained material only with difficulty. Neither May-Grünwald-Giemsa stain nor fluorescence microscopy under ultraviolet light were effective for routine investigation.

The importance of Pneumocystis carinii as a lethal opportunistic pathogen in immunocompromised patients is now widely recognised. ${ }^{1-4}$ Untreated pneumocystis pneumonia is almost invariably fatal, and survival depends on early specific antimicrobial treatment. ${ }^{5}$ Discovering the exact aetiology of respiratory distress in immunosuppressed patients is, however, often difficult as the possible causes are many and the symptoms, clinical signs, and radiographical features are generally non-specific. Culture of the human strain of $P$ carinii is unsuccessful, and serology is unreliable in immunodeficient subjects. Definitive diagnosis must be made by morphological identification of the organism. The value of cytological examination of bronchoalveolar lavage fluid as an investigative technique in immunocompromised patients with pulmonary infiltrates has been reported previously. ${ }^{67}$

\section{Material and methods}

Over four years bronchoalveolar lavage was performed 62 times on 53 immunosuppressed patients during 60 episodes of pneumonia. Series $I^{7}$ contained
26 patients (30 examinations) and series II an additional 27 patients (32 examinations). Seven patients underwent lavage twice for different episodes of pulmonary illness, and one patient was examined three times during the course of the same episode. The lavage fluid was collected and processed for cytology by the methods previously described. ${ }^{6}$ Specimens from series I were stained by Papanicolaou, MayGrünwald-Giemsa, Ziehl-Neelsen, and Grocott methenamine silver methods, with the addition of Perls's and Gram stains only if these seemed appropriate after preliminary microscopy. In series II the Gram stain (with carbol fuchsin) was performed on all specimens and the slides examined for evidence of $P$ carinii, as described by Macher et al. ${ }^{8}$ The Papanicolaou stained slides from series II were also retrospectively reviewed using fluorescence microscopy, according to the method of Ghali et al. ${ }^{9}$

\section{Results}

A total of 15 cases of $P$ carinii pneumonias were diagnosed during the four years. The table shows the age, primary medical condition, cytological findings, and outcome of the illness for each of the patients. Cases 1 to 8 are from series $I$ and cases 9 to 15 are from series II. Case 15 was examined three times. Apart from one early case with acute lymphoblastic leu- 
Table

\begin{tabular}{|c|c|c|c|c|c|}
\hline Case No & Sex & Age & Primary medical condition & Cytological findings & Outcome \\
\hline $\begin{array}{r}1 \\
2 \\
3 \\
4 \\
5 \\
6 \\
7 \\
8 \\
9 \\
10 \\
11 \\
12 \\
13 \\
14 \\
15\end{array}$ & $\begin{array}{l}\mathbf{M} \\
\mathbf{M} \\
\mathbf{F} \\
\mathbf{F} \\
\mathbf{M} \\
\mathbf{M} \\
\mathbf{M} \\
\mathbf{M} \\
\mathbf{M} \\
\mathbf{F} \\
\mathbf{F} \\
\mathbf{F} \\
\mathbf{M} \\
\mathbf{M} \\
\mathbf{F}\end{array}$ & $\begin{array}{l}16 \\
61 \\
29 \\
24 \\
51 \\
26 \\
45 \\
43 \\
50 \\
54 \\
41 \\
47 \\
53 \\
26 \\
54\end{array}$ & $\begin{array}{l}\text { Leukaemia } \\
\text { Renal transplant } \\
\text { Systemic lupus erythematosus } \\
\text { Systemic lupus erythematosus } \\
\text { Renal transplant } \\
\text { Renal transplant } \\
\text { Renal transplant } \\
\text { Renal transplant } \\
\text { Renal transplant } \\
\text { Renal transplant } \\
\text { Renal transplant } \\
\text { Renal transplant } \\
\text { Renal transplant } \\
\text { Renal transplant } \\
\text { Renal transplant }\end{array}$ & $\begin{array}{l}P \text { carinii, Candida } \mathrm{Sp} \\
P_{\text {carinii, }} \text { Candida } \mathrm{Sp} \\
P_{\text {carinii }} \\
P_{\text {carinii }} \\
P \text { carinii } \\
P \text { carinii } \\
P_{\text {carinii }} \\
P_{\text {carinii }} \\
P_{\text {carinii }} \\
P_{\text {carinii, }} \text { Candida } \mathrm{Sp} \\
P_{\text {carinii, }} \text { cytomegalovirus } \\
P_{\text {carinii }} \\
P_{\text {carinii }} \\
P \text { carinii } \\
\text { (i) } P \text { carinii, cytomegalovirus } \\
\text { (ii) } P \text { carinii } \\
\text { (iii) } P \text { carinii, cytomegalovirus }\end{array}$ & $\begin{array}{l}\text { Recovered } \\
\text { Recovered } \\
\text { Recovered } \\
\text { Recovered } \\
\text { Recovered } \\
\text { Recovered } \\
\text { Recovered } \\
\text { Recovered } \\
\text { Died } \\
\text { Recovered } \\
\text { Died } \\
\text { Recovered } \\
\text { Died } \\
\text { Recovered } \\
\\
\text { Died }\end{array}$ \\
\hline
\end{tabular}

kaemia all the patients were from the renal unit and receiving immunosuppressive treatment either for lupus glomerulonephritis or following renal transplantation. The 14 cases of $P$ carinii pneumonia in the renal unit occurred in two clusters, each of six months' duration, separated by an interval of two years. In all instances the bronchoalveolar lavage fluid presented a characteristic appearance when stained by the Papanicolaou technique. The most striking feature was the presence of abundant foamy debris, which displayed considerable depth of focus. At high magnification the debris had a spongy "honeycomb" texture with numerous small clear circles surrounded by amorphous material. Some dense aggregates showed biphasic staining (fig 1).

The numbers of leucocytes and alveolar macrophages were low. As might be expected, paucity of leucocytes is common in bronchoalveolar lavage fluid from immunodeficient subjects but alveolar macrophages are generally plentiful. This combination of honeycomb debris and reduced macrophages was seen only in the Papanicolaou stained slides of patients who were found to have $P$ carinii infection. Definitive diagnosis, however, requires actual identification of the cystic forms or trophozoites of $P$ carinii, and these are not visualised by the Papanicolaou technique. Cysts of $P$ carinii stain black with Grocott methenamine silver, and on all 15 occasions were readily found within the aggregates of the foamy debris. (fig 2). They were not identified lying free in the fluid or within macrophages. Cysts have thin walls and contain two small "comma shaped" structures. Collapsed cysts have a characteristic "cup like" appearance. Trophozoites do not stain with Grocott. In two cases in series II small numbers of cysts with eight internal sporozoites were clearly seen on the slides stained with Gram (fig 3). In the other cases they were found only with great difficulty. Diagnostic organisms could not be identified with certainty in any of the preparations stained with Man-GrünwaldGiemsa. The Papanicolaou stained slides from series II were retrospectively reviewed under ultraviolet illumination with a fluorescence microscope. Where the foamy debris showed a biphasic reaction with the Papanicolaou stain, there was background fluorescence of the orangeophilic stained material. This impeded visualisation of diagnostic cystic organisms. Occasional cysts, showing faint fluorescence, were identified around the periphery of some of the masses of debris, but it was impossible to distinguish confidently these from erythrocytes which also displayed some fluorescence, withouf reviewing the same field with conventional light microscopy. Ingested dust particles and erythrocytes within the small numbers of alveolar macrophages present also exhibited fluorescence.

Case 15 was examined three times during the course of the same illness, and $P$ carinii was identified on each occasion.. In two of these specimens "owl's eye" inclusions (fig 4) indicative of cytomegalovirus infection were seen in addition to $P$ carinii. Cytomegalovirus was also diagnosed in case 11 , and fungal spores and pseudohyphae consistent with Candida sp were found in the fluid from cases 1,2 , and 10 . Two of the patients who recovered from pneumocystis pneumonia became ill a second time; one developed pulmonary tuberculosis and the other invasive candidiasis.

\section{Discussion}

$P$ carinii was first recognised as a cause of epidemic pneumonia during the second world war, ${ }^{10}$ although the initial description is generally attributed to Chagas. ${ }^{11}$ Expansion of organ transplant programmes, improved survival in haematological malignancies, and since $1981,{ }^{12}$ the acquired immune deficiency syndrome (AIDS) have all contributed to 
Diagnosing pneumocystic carinii pneumonia

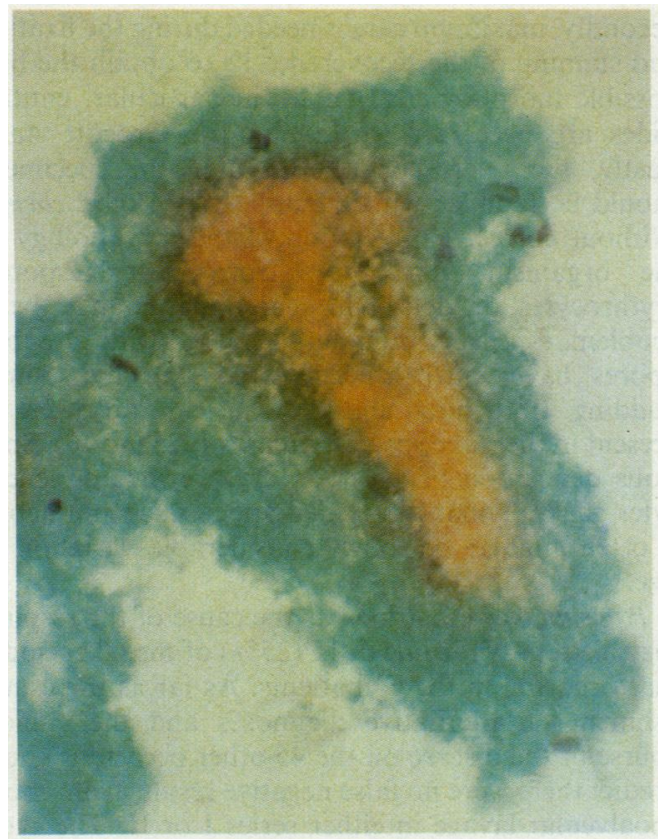

Fig 1 Foamy "honeycomb" debris in lavage fluid from patient with $P$ carinii pneumonia. This three dimensional aggregate shows biphasic staining, a feature often, but not invariably, present. (Papanicolaou). $\times 560$.

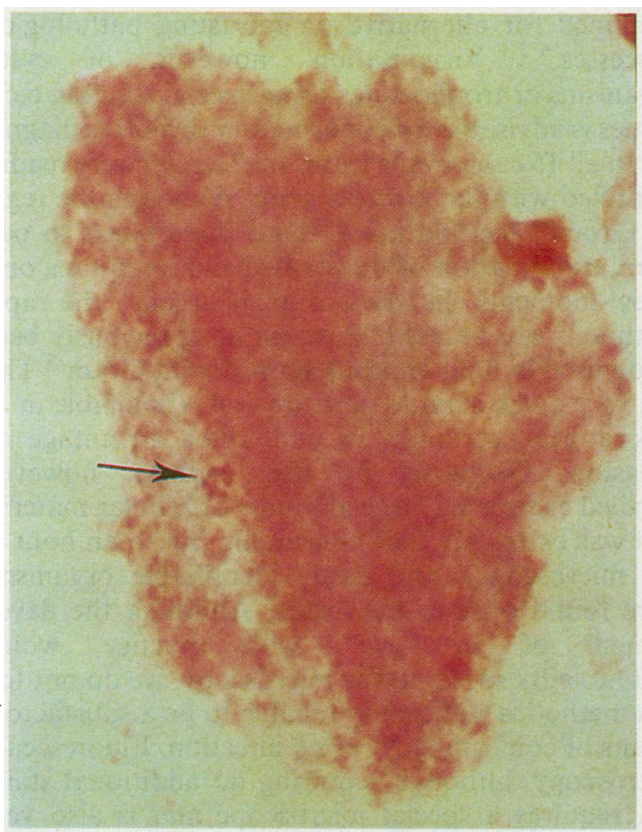

Fig 3 Intracystic sporozoites of $P$ carinii (arrow) among aggregate of debris containing weakly staining free trophozoites. (Gram.) $\times 1000$.

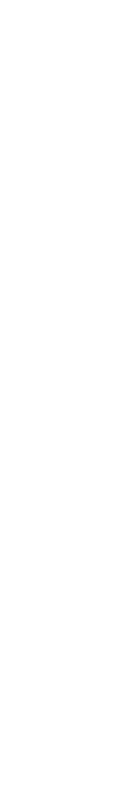

Fig 2 Cystic organisms of $P$ carinii in mass of foamy debris. (Grocott.) $\times 1000$.

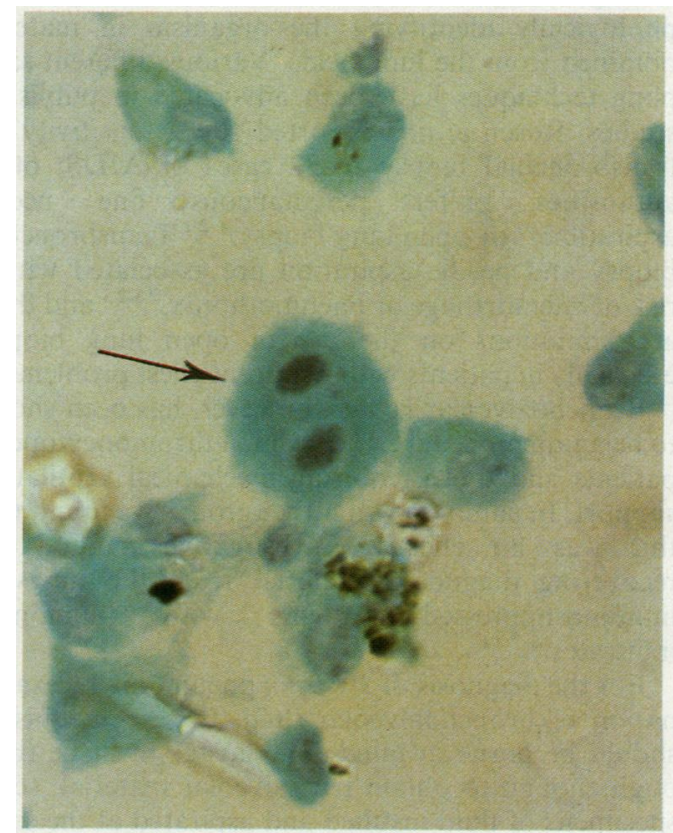

Fig 4 Binucleate cell (arrow) containing "owl's eye" inclusions characteristic of cytomegalovirus infection. (Papanicolaou.) $\times 1000$. 
an increase in immunocompromised subjects at risk and a rise in the number of reported cases of this formerly rare type of opportunistic pneumonia. ${ }^{513-18}$ Experience in Britain, however, is still limited $^{16-18}$ and diagnosis is considered to be problematic. ${ }^{18}$ Untreated pneumocystis pneumonia is almost always fatal, but apart from those with AIDS, about $80 \%$ of adults recover after being given cotrimoxozole. ${ }^{19}$ The long term prognosis for renal transplantation recipients is generally excellent, providing they do not succumb to infection. ${ }^{20}$ Although chemoprophylaxis has been shown to be effective in paediatric oncology clinics, ${ }^{21}$ clinical anxiety remains concerning recent reports of adverse reactions to cotrimoxazole in adults, ${ }^{22}{ }^{23}$ and toxicity is known to occur with the alternative administration of pentamidine ${ }^{24}$ Potential for recovery, therefore, depends on prompt specific treatment early in the course of the disease $^{5}$ : if undesirable multiple empirical treatments are to be avoided rapid definitive diagnosis of $P$ carinii infection is imperative.

Patients with pneumocystis pneumonia present with a progressive lung infiltrate of unknown aetiology. Possible causes are many and include bacterial, fungal and viral infections, pulmonary haemorrhage, malignant infiltration, and drug or radiation toxicity. At present, the only reliable method of distinguishing $P$ carinii infection is by morphologically identifying the organism in material obtained from the lung fields. Various different sampling techniques have been advocated in published studies. Rosen et $a^{25}$ reported $100 \%$ sensitivity for transbronchial biopsy in 32 cases of AIDS; other authorities prefer percutaneous fine needle aspiration ${ }^{26}$ or open lung biopsy. ${ }^{127}$ Transbronchial biopsy and needle aspiration are associated with a risk of haemorrhage or pneumothorax,${ }^{2628}$ and there are limitations on the use of open lung biopsy, especially in patients with recurrent chest problems. ${ }^{29}$

Bronchoalveolar lavage, however, has been shown to be a safe procedure, ${ }^{3021}$ even in thrombocytopenic patients and those requiring mechanical ventilatory support. In common with other groups we found that this was an effective investigative method for recovering diagnostic material from the lungs of immunosuppressed patients with pulmonary infiltrates. ${ }^{6731}$

For the diagnosis of $\boldsymbol{P}$ carinii pneumonia by examination of bronchoalveolar fluid, three prerequisites should be borne in mind. The lavage must be thorough enough to obtain true alveolar material: serial specimens of fluid instilled and aspirated at the same site are generally required to ensure this, as the first aliquot usually contains only bronchial debris, and alveolar contents containing $P$ carinii may not be
Secondly, maximum care is needed during the fixation and staining of the recovered cells to obtain the best possible morphological detail: in particular, control slides are necessary for timing the Grocott stain. Lastly, the microscopist examining the specimens should be familiar with the appearance of $P$ carinii. Without correct appreciation of the morphology of the organism, distinction from fungal spores, erythrocytes or debris in macrophages may be a problem, especially in material stained with Grocott. Spores have much thicker walls and may show budding. Both fungi and $P$ carinii can, however, be present in the same specimen (cases 1,2, and 10). Spurious deposition of silver on erythrocytes or leucocytes generally has a speckled appearance and debris is often angular or shows considerable variation in size.

$P$ carinii was confirmed as the cause of the respiratory distress syndrome in $15(25 \%)$ of the 60 episodes that occurred in the 53 patients. As far as the establishment of alternative diagnoses and the clinical course of the disease on the 45 other occasions could predict there were no false negative results from bronchoalveolar lavage in either series I or II. The cytological picture of "honeycomb" debris and few macrophages, when seen in Papanicolaou stained lavage fluid, is sufficiently distinctive to permit a rapid preliminary diagnosis of pneumocystis pneumonia frono the initial routine slides, which, of course, can also be examined for alternative or coexisting pathologica $\overline{\text { क }}$ processes. $^{67}$ Visualisation, however, of cystie ${ }^{2}$ organisms or trophozoites using special staining techniques is advisable for confirmatory definitive diagnosis. In all 15 cases cystic forms of $P$ carinii were readily identified with the Grocott stain. Although the regular Grocott method takes about three hours to perform, examination of the stained slides requires only a few moments. In cases of great urgency the rapid method $^{32}$ can be used. $P$ carinii has previously been recognised in lung imprints stained with Gram. ${ }^{8}$ This is a very quick stain to perform and is available in all laboratories, certainly an undoubted advantage on occasion. Diagnosis by this method, however, entailed examining large amounts of cellular material and was extremely time consuming (up to an hour at the microscope), and easily identifiable organisms were found only in two cases. Although the development of an "eye", with practice, would undoubtedly speed up the microscopy, we do not feel this method is sufficiently reliable to be a satisfactory means of confirming $P$ carinii infection. Fluorescence microscopy, although requiring no additional staining, requires a special microscope and is also very tedious to perform. We agree with Ghali et al ${ }^{9}$ that the technique is no faster than the Grocott stain when 
ence this was not found to be a suitable alternative to silver staining. Fluorescence microscopy may have a place in retrospective searches of archival material, but silver techniques can, if necessary, be satisfactorily performed on slides already stained with Papanicolaou. We were unable to see organisms in material stained with Man-Grünwald-Giemsa, although some authorities ${ }^{33}$ recommend this method.

In conclusion, if facilities for fibreoptic bronchoscopy and cytopathology are available examination of bronchoalveolar lavage fluid is an efficient method for the diagnosis of $P$ carinii pneumonia. Bronchoalveolar lavage avoids the risk of haemorrhage or pneumothorax and achieves extensive alveolar sampling. With the routine Papanicolaou stain the appearance is sufficiently distinctive to permit rapid preliminary diagnosis while at the same time the specimens can be examined for other abnormalities, such as evidence of cytomegalovirus. Grocott methenamine silver staining can be readily performed on the lavage material and remains the best confirmatory technique.

We thank the clinicians from the department of medicine, who performed the bronchoalveolar lavage, especially Dr JM Hopkin, who examined all the patients in series $\mathrm{I}$. We also thank Mr WP Cuthbertson for technical help and Mrs Joyce Cheney for typing the manuscript.

The colour photography was financed by a grant from the Renal Research Fund of the Queen Elizabeth Hospital, for which we are extremely grateful.

\section{References}

1 Haselton PS, Curry A. Pneumocystis carinii: the continuing enigma. Thorax 1982;37:481-5.

2 Kay SB. Pneumocystis pneumonia. Br Med J 1983;286:499-500.

3 Anonymous. Pneumocystis-an orphan organism? [Editorial] Lancet 1985;i:676-7.

4 Macfarlane JJ, Finch RG. Pneumocystis carinii pneumonia. Thorax 1985;40:561-70.

5 Rubin RH, Wolfson JS, Cosimi AB, Tolkoff-Rubin NE. Infection in the renal transplant recipient. Am J Med 1981;70:405-11.

6 Hopkin JM, Young JA, Turney JH, Adu D, Michael J. Rapid diagnosis of obscure pneumonia in immunosuppressed renal patients by cytology of alveolar lavage fluid. Lancet 1983;ii:299-301.

7 Young JA, Hopkin JM, Cuthbertson WP. Pulmonary infiltrates in immunocompromised patients: diagnosis by cytological examination of bronchoalveolar lavage fluid. J Clin Pathol 1984;37:390-7.

8 Macher AB, Shelhamer J, Maclowry J, Parker M, Masur H. Pneumocystis carinii identified by Gram stain of lung imprints. Ann Intern Med 1983;99:484-5.

9 Ghali VS, Garcia RL, Skolom J. Fluorescence of Pneumocystis carinii in Papanicolaou smears. Hum Pathol 1984;15:907-9.

10 Gajdusek DS. Pneumocystis carinii-etiological agent of interstitial plasma cell pneumonia of premature and young infants. Pediatrics 1957;19:543-65.

11 Dutz W. Pneumocystis carinii. Pathol Annu 1970;5:309-41.

12 Gottlieb MS, Schroff R, Shanker HM. Pneumocystis carinii pneumonia and mucosal candidiasis in previously healthy homosexual men: evidence of a new acquired cellular immunodeficiency. $N$ Engl J Med 1981;301:1425-30.

13 Kuller J, First MR, D'Achiardi R, Munda R. Pneumocystis carinii pneumonia in renal transplant recipients. Am J Nephrol 1982;2:213-5.

14 Murray JF, Felton CP, Garay SM, et al. Pulmonary complications of the acquired immune deficiency syndrome. $N$ Engl $J$ Med 1984;310:1682-8.

15 Marchevsky A, Rosen MJ, Chrystal G, Kleinerman J. Pulmonary complications of the acquired immunodeficiency syndrome: a clinicopathologic study of 70 cases. Hum Pathol 1985;16: 659-70.

16 Haselton PS, Curry A, Rankin EM. Pneumocystis carinii pneumonia: a light microscopical and ultrastructural study. J Clin Pathol 1981;34:1138-46.

17 Swinburn CR, Pozniak AL, Sutherland S, Banks RA, Teall AJ, Johnson NMCI. Early experience and difficulties with bronchoalveolar lavage and transbronchial biopsy in the diagnosis of AIDS associated pneumonia in Britain. Thorax 1985;40:166-70.

18 Ballardie FW, Winearls CG, Cohen J, Carr DH, Rees AJ, Williams G. Pneumocystis carinii pneumonia in renal transplant recipients-clinical and radiographic features, diagnosis and complications of treatment. $Q J$ Med 1985;57:729-47.

19 Young LS. Trimethoprim-sulphamethoxazole in the treatment of adults with pneumonia due to Pneumocystis carinii. Rev Infect Dis 1982;4:608-13.

20 Ramsay PG, Rubin RH, Tolkoff-Rubin NE, Cosmi AB, Russell PS, Greene R. The renal transplant patient with fever and pulmonary infiltrates: etiology, clinical manifestations, and management. Medicine 1980;59:206-22.

21 Hughes WT. Five-year absence of Pneumocystis carinii pneumonitis in a paediatric oncology centre. $J$ Infect Dis 1984;150:305-6.

22 Gordin FM, Simon GL, Wolsy CB, Ills J. Adverse reactions to trimethoprim-sulphamethoxazole in patients with the acquired immunodeficiency syndrome. Ann Intern Med 1984;100:495-9.

23 Committee on Safety in Medicines. Deaths associated with cotrimoxazole, ampicillin and trimethoprim. Current Problems 1985;15:1.

24 Walzer PD, Perl DP, Krogstad DJ, Rawson PG, Schultz MG. Pneumocystis carinii pneumonia in the United States. Ann Intern Med 1974;80:83-93.

25 Rosen MJ, Tow TWY, Teirstein AS, Chuang MT, Marchevsky A, Bottone J. Diagnosis of pulmonary complications of the acquired immune deficiency syndrome. Thorax 1985;40:571-5.

26 Castellino RA, Blank N. Etiologic diagnosis of focal pulmonary infection in immunocompromised patients by fluoroscopically guided percutaneous needle aspiration. Radiology 1979;132: 563-7.

27 Groeve AH, Saul VA, Aki BF. Role of different methods of lung biopsy in the diagnosis of lung lesions. Am Rev Respir Dis 1982;125:601-3.

28 Matthay RA, Moritz ED. Invasive procedures for diagnosing pulmonary infection: a critical review. Clinics in Chest Medicine 1981;2:3-18.

29 Puksa S, Hutcheon MA, Hyland RH. Usefulness of transbronchial biopsy in immunosuppressed patients with pulmonary infiltrates. Thorax 1983;38:146-50.

30 Strumpf IJ, Feld MK, Cornelius MJ, Keogh BA, Crystal RG. Safety of fibreoptic bronchoalveolar lavage in evaluation of interstitial lung disease. Chest 1981;80:268-71.

31 Stover DE, Zaman MB, Hajdu SI, Lange M, Gold J, Armstron D. Bronchoalveolar lavage in the diagnosis of diffuse pulmonary infiltrates in the immunosuppressed host. Ann Intern Med 1984;101:1-7.

32 Mahan CT, Sale GE. Rapid methenamine silver stain for pneumocystis and fungi. Arch Pathol Lab Med 1978;102:351-2.

33 Dunnill MS. Pulmonary pathology. Edinburgh: Churchill Livingstone, 1982:173-6.

Requests for reprints to: Dr Jennifer A Young, Department of Pathology, The Medical School, University of Birmingham, Birmingham B15 2TJ, England. 